\title{
Reflux Esophagitis and Marginal Ulcer after Pancreaticoduodenectomy
}

\author{
Selina Buchner • Georg O. Spaun • \\ Dietmar Öfner-Velano
}

Received: 14 June 2011 / Accepted: 26 October 2011 / Published online: 17 November 2011

(C) 2011 The Society for Surgery of the Alimentary Tract

\section{Dear Editor,}

We read with great interest the article by Jin-Ming Wu et al. $\left[{ }^{1}\right]$ published in issue 15 of the Journal of Gastrointestinal Surgery 2010, in which the authors reported about reflux esophagitis and marginal ulcer after pancreaticoduodenectomy. The authors cover an important issue which is sparsely approached in the literature and most data result from older publications. In this study, reflux esophagitis and marginal ulcer after standard pancreaticoduodenectomy and pyloruspreserving pancreaticoduodenectomy were analysed in 371 patients.

There are, however, few issues we could not clarify while reading this manuscript. Firstly, we were confused by the different number of patients mentioned in the result and discussion part (Table 1). Secondly, the authors mentioned in Table 1 that pancreaticoduodenectomy for chronic pancreatitis was not a significant risk factor for the development of marginal ulcer. However, we could find only vague description of the patients' pathology in the study population. We think it would be of interest to know how many patients in the study group suffered from cancer, chronic pancreatitis or benign pancreatic disease.

Thirdly, the authors did not clarify how the integrity of the TA 30-3,5 stapler closure of the afferent limb, used for the uncut Roux-en-Y reconstruction, was investigated. Fistulation through the stapler closure could have been a
Table 1 Data on pancreaticoduodenectomy for chronic pancreatitis

\begin{tabular}{llll}
\hline OP procedure & Patients & Results & Discussion \\
\hline PD & 158 & & \\
PD + Roux-en-Y & 110 & $7 / 109(p=0.042)$ & $8 / 103(p=0.04)$ \\
PD - Roux-en-Y & 48 & $8 / 49$ & $7 / 40$ \\
PPPD & 213 & & $16 / 141$ \\
PPPD + Roux-en-Y & 157 & $16 / 157$ & $9 / 47$ \\
PPPD - Roux-en-Y & 56 & $9 / 56$ & \\
\hline
\end{tabular}

$O P$ operative, $P D$ pancreaticoduodenectomy, $P P P D$ pyloruspreserving pancreaticoduodenectomy, + with Roux-en-Y reconstruction, - without Roux-en-Y reconstruction

co-factor for higher incidence of marginal ulcer in the Roux-en-Y group.

Yours sincerely,

Selina Buchner, MD; Georg Spaun MD, Dietmar Öfner, MD, MSc., FACS

Paracelsus Private Medical University, Salzburg, Austria

\section{Reference}

1. Wu JM, Tsai MK, Hu RH, Chang KJ, Lee PH, Tien YW. Reflux esophagitis and marginal ulcer after pancreaticoduodenectomy. J Gastrointest Surg. 2011 May;15(5):824-8. Epub 2011 Feb 24.
S. Buchner $(\varangle) \cdot$ G. O. Spaun $•$ D. Öfner-Velano Department of Surgery, Paracelsus Private Medical University, Müllner Hauptstrasse 48,

5020 Salzburg, Austria

e-mail: s.buchner@salk.at 